\title{
Biotope associations and the decline of bumblebees (Bombus spp.)
}

D. Goulson*, M.E.Hanley, B. Darvill and J.S. Ellis

*Author for correspondence

School of Biological Sciences, Biomedical Sciences Building, Bassett Crescent East, Southampton SO16 7PX

Tel: +44-23-80594212

Fax: +44-23-80594269

Email: DG3@soton.ac.uk

Key Words: Hymenoptera; Bombus; abundance; rarity; specialization 


\section{Abstract}

Much of the ecology of rare bumblebee species remains poorly understood and in need of further study. It has recently been suggested that differences in the range and rate of decline among bumblebee species may relate to differences in their degree of habitat specialization. We examine biotope use by 17 bumblebee species in the Hebrides, southern UK and South Island, New Zealand. We identify a cluster of widespread and abundant species that occur in almost all biotopes and exploit man-made environments such as gardens and arable margins; this group corresponding to the “mainland ubiquitous” species of previous studies. A second grouping of species includes those associated to varying degrees with heathland. It is notable that some species occupy markedly different biotopes in different parts of their range; for example B. soroeensis is found largely on upland heaths in the Hebrides, but on calcareous grassland in the south. Some species, such as $B$. subterraneus and B. distinguendus, now survive only in specific rare biotopes and could be mistaken for habitat specialists, but it is clear from their historic distributions that they formerly occupied a broader range of biotopes. Surviving populations of several of the species that have declined most ( $B$. distinguendus, B. sylvarum, B. muscorum sladeni, B. humilis) exhibit a markedly coastal distribution, when once they were widespread inland. We suggest that this is probably simply because some coastal biotopes are less amenable to agricultural improvement, and so more have escaped the detrimental effects of intensive farming. Our results concur with previous suggestions that bumblebees are generally not habitat specialists, so that the conservation of most bumblebee species could be achieved by restoration of flower-rich unimproved meadows. 


\section{Introduction}

Pollinators in general and bumblebees in particular have suffered declines in abundance and range contractions in the last 60 years, across much of western Europe and North America (Williams, 1982, 1986; Rasmont, 1995; Kosior, 1995; Buchmann and Nabhan, 1996; Westrich, 1996; Westrich et al., 1998, Goulson 2003). Of the 25 bumblebee species known from the UK, three species are extinct and many more have undergone significant range contractions, with the possibility of further UK extinctions in the near future (Alford 1975; Edwards 1998, 1999, 2000, 2001). It is widely accepted that these declines are linked to the intensification of farming practices, although much of the evidence is anecdotal (Williams, 1986; Osborne and Corbet, 1994; Goulson, 2003).

The plight of our bumblebee fauna deserves particular attention because many other organisms are dependent on bumblebees for their survival. A large number of wild plants are pollinated predominantly or exclusively by bumblebees, sometimes by particular species of bumblebee (Corbet et al., 1991; Osborne et al., 1991). Thus, it seems probable that reductions in the abundance and species richness of bumblebees may lead to widespread changes in plant communities (Corbet et al., 1991). These changes will have further knock-on effects for associated herbivores and other animals dependent on plant resources. In addition, bumblebee nests support a suite of commensal, parasitic and parasitoid species (Alford 1975, Goulson 2003).

A small number of bumblebee species (6 in the UK) seem to have been largely unaffected by changes to the environment in the last 60 years, and so far as can be established have suffered no declines in either abundance or range and remain more or less ubiquitous. These species appear to be more generalized in their foraging preferences than some of the rare species, which perhaps explains their ability to adapt (Goulson et al. 2005). However, both common and rare species overlap greatly in their forage use, with almost all species preferring to collect pollen from Fabaceae.

Williams (2005) recently showed that rare and declining species in Britain tend to have small geographic ranges within Europe. He suggests that these species may have more specific habitat 
associations, which render them more susceptible to environmental change. However, very little is known about the habitat requirements of bumblebees. Indeed knowledge of all aspects of the ecology of the rarer species of bumblebee is very limited. Ecological studies of rare and declining species are urgently needed if appropriate conservation measures are to be deployed. Here we examine the biotopes occupied by 16 of the 17 extant 'true' bumblebee species in the UK, and also biotope use in the four bumblebee species found in New Zealand which include B. subterraneus, now extinct in the UK. We exclude the socially parasitic 'cuckoo' bumblebees (subgenus Psithyrus) because their distributions are presumably governed largely by that of their hosts.

\section{Methods}

We collected data on the presence or absence of bumblebee species at 70 sites in southern and central UK (Salisbury Plain, S. Wales, S. Essex, N. Kent, Dungeness, Somerset levels; S. Hampshire and Hertfordshire), 70 sites in central south Island, New Zealand, and 14 islands in the Hebrides, UK (Canna, Rum, Muck, Eigg, Coll, Tiree, Colonsay, Staffa, Lunga, Barra, Muldoanich, Pabbay, Mingulay and Sandray). Sites were chosen to span the range of biotopes present, and in many cases were also chosen on the basis of prior knowledge as to the presence of rare bumblebee species. The New Zealand bumblebee fauna was deliberately introduced at the end of the $19^{\text {th }}$ century from the UK (Hopkins 1914). Clearly the ecology of these species in New Zealand may be markedly different to that in the UK, and this must be born in mind when interpreting the results. The reason for including the New Zealand data is a practical one; one of the species present there, B. subterraneus, is extinct in the UK and exceedingly rare in most of Europe, so that New Zealand is the only place known to the authors where it can be observed in any numbers.

Studies were carried out between June and August 2002 - 4 (southern UK), January 2003 (New Zealand), and June - August 2003 - 4 (Hebrides). Each site was searched for one man hour, or until the searcher was satisfied that there were unlikely to be further undetected bee species. In the 
Hebrides, separate searches were conducted in the different biotopes that were present on each island. All searches were conducted between $0800 \mathrm{~h}$ and $1700 \mathrm{~h}$, and during warm dry weather favourable to bee activity. Species that are difficult to distinguish on the wing, such as B. humilis and B. muscorum, were captured and examined with a hand lens. For B. muscorum, three morphologically distinct subspecies were present in the study areas, and separate records were kept for each. In the UK, biotopes were broadly classified into phase one habitat survey categories (Anon 1990). Modifications to these categories were necessary in New Zealand. Some sites contained more than one biotope type.

The proportion of occupied sites for each bee species found in each of the different biotope types was examined using principal components analysis in SPSS 11.0, with separate analyses for southern UK, the Hebrides and New Zealand.

\section{Results and Discussion}

It must be borne in mind that in both southern UK and New Zealand, searches were targeted at areas where the rarer bees were known to occur, so the frequency of occurrence of rare bee populations is far higher than would be expected if these biotopes were searched at random. In fact for B. sylvarum and B. muscorum sladeni (the English race) all known populations were included.

\section{Southern UK}

Some species, such as B. terrestris and B. pascuorum, were almost ubiquitous in southern UK, occurring in such diverse biotopes as coastal shingle, fens, gardens, woodland and arable margins (Table 1). A further four species were very widespread (B. lapidarius, B. pratorum, B. hortorum, B. lucorum). Together, these six species correspond to the "mainland ubiquitous" species of Williams (1982). They are all widespread in Europe and, with the possible exception of the long-tongued $B$. hortorum, are known to have broad diets (Williams 1982, 1989, 2005; Goulson et al. 2005). This 
presumably explains, at least in part, why they flourish in diverse biotopes. These six species cluster together in the principal components analysis of the southern UK data (Figure 1a), largely due to their frequent presence in arable margins and gardens, biotopes in which none of the other bumblebee species were recorded. Interestingly, B. hypnorum also falls within this group. This species was first recorded in the UK near Southampton on the south coast in 2001 (Goulson and Williams 2001). This continental European species appears to be one of few species of bumblebee which has undergone range expansions in recent years. It is not clear how it crossed the Channel to the UK, but it seems to be largely associated with gardens at present. Its UK range has expanded north as far as Hertfordshire although it remains a scarce species (D.G. unpublished data).

A second cluster of species, B. sylvarum, B. humilis and B. muscorum sladeni, were associated with coastal biotopes (dunes, grazing marshes and shingle), and with the exception of Salisbury Plain which supports all three species, almost all known populations are coastal. A third loose grouping of species (B. ruderatus, B. soroeensis and B. ruderarius) is associated with calcareous grassland, although it must be noted that the numbers of populations recorded for all three were very low. It is also interesting to note that $B$. ruderarius was frequently encountered in urban gardens in Leicester until the mid 1980s (Owen 1991). This species appears to have undergone a particularly marked decline in recent decades which remains unexplained, particularly since it was once an inhabitant of urban gardens which are still present in abundance throughout the UK. Perhaps the urban populations were maintained by immigration from surrounding areas which have since become degraded.

The only remaining southern UK species, B. jonellus, was recorded in gardens, lowland heath and on calcareous grassland, three rather different biotopes.

\section{Hebrides}

Three of the "mainland ubiquitous" species, B. pascuorum, B. hortorum and B. lucorum were strongly associated with gardens, road verges and semi-improved grassland, similar disturbed 
biotopes to those in which they occur in southern UK (Figure 1b). B. jonellus and the rarely recorded B. soroeensis were separated from the other species by their strong preference for upland heath. The very rare $B$. distinguendus was only recorded on machair and on nearby dunes. The remaining species were quite generalised, being recorded in a range of biotopes. It is noteworthy that $B$. muscorum is almost ubiquitous in the Hebrides and is often the most abundant species, in stark contrast to the situation in England and Wales. B. muscorum smithianus is particularly frequent on heaths, a biotope in which it does not occur in southern UK.

\section{New Zealand}

Of the four UK bumblebee species now in New Zealand, only B. subterraneus shows any strong biotope preference. Most populations were found on the shingle margins of large lakes, and all of the individuals recorded were within $\sim 1 \mathrm{~km}$ of a lake. The two closely related long-tongued species, $B$. hortorum and B. ruderatus were found in similar biotopes (road verges, shingle river margins, improved pasture and non-native scrub). As in the UK, B. terrestris was ubiquitous, being found in all biotopes including native New Zealand forests where the other bumblebee species do not occur. It is notable that the pattern of abundance of these four species is identical to that found in the UK (B. terrestris $>$ B. hortorum $>$ B. ruderatus $>$ B. subterraneus). B. subterraneus was only found at sites where all three of the other species were present.

\section{Synthesis}

A striking feature of these data is that all bumblebee species were found in more than one biotope, and most species were found across a broad range of biotopes (Table 1). Even very rare species often do not appear to have tight biotope associations. For example B. sylvarum is probably the second rarest extant bee species in the UK, with about 7 surviving populations, yet these are found in such diverse biotopes as the Somerset levels (fenland) and the dry calcareous grasslands of Salisbury Plain, two biotopes that have few plant species in common. B. muscorum sladeni and B. humilis are 
also rare but survive in a range of different biotopes. If these species are not dependent on particular biotopes, why are they rare? The answer may be that although these species occur in diverse biotopes all of these biotopes are themselves rare. The area of calcareous grassland in the UK has declined by $>98 \%$ in the last 60 years (Howard et al., 2003), while marshes and fens have been extensively drained. Many bumblebee species that are now rare or extinct in the UK were once much more widespread (Alford 1980), and must have occurred in a much broader range of biotopes. For example B. distinguendus is now exceedingly rare and found only in a few areas of machair and dunes in the far north and west of Scotland. Yet it is clearly not a machair specialist; its former distribution spans 75, 50 km cells (Williams 2005) and covers the entire country south to Cornwall, with numerous inland records from, for example, Oxfordshire, Warwickshire and Berkshire. Similarly, $B$. subterraneus appears to be restricted to the vicinity of lakes in New Zealand, particularly shinglecovered lake margins where there is plenty of its favoured foodplant, Trifolium pratense (Goulson and Hanley 2004). The last known population in the UK (which became extinct in about 1988) was on the coastal shingle at Dungeness. Yet, clearly in the past this species was not confined to shingle (a very rare habitat in Europe), for in the UK it was once distributed throughout the south, the Midlands and East Anglia (Alford 1980).

It is notable that almost all of the sites with high bumblebee species richness in the UK are now coastal, and it is unclear why this should be. Coastal populations of rare bees occupy very varied biotopes (marshes, dunes, calcareous grassland, shingle). What feature do these biotopes have in common that allow them to support these rare bumblebee species? It seems probable that they all have a higher floral density and diversity than the intensively farmed countryside that comprises most of the British landscape. Declines in British flora as a result of agricultural intensification are well documented, and have occurred over a similar timescale to the contractions of bumblebee distributions (Grime et al., 1988; Rich and Woodruff, 1996). A particular change likely to have had a major impact on bumblebees is the switch from hay to silage production (Rasmont 1988). Fabaceae are among the favoured food sources of almost all UK bumblebee species (Goulson et al. 2005), and 
hay meadows are rich in Fabaceae such as Trifolium and Lotus. Large tracts of the farmed lowlands of the UK probably once supported high densities of wildflowers in hay meadows, unimproved pasture and hedgerows, so that currently rare bumblebee species were once widespread. The contraction of rare bumblebee populations to coastal sites may simply be because coastal biotopes such as dunes, shingle and marshes are relatively infertile and unproductive for agriculture, and so have been more likely to escape the negative effects of intensive farming. That there is not some factor present only in coastal sites that is essential to these rare bee species is demonstrated by both the large former ranges of these species and by the survival of many rare species on Salisbury Plain (Goulson and Darvill 2004), the largest tract of England to have escaped intensive cultivation through its status as a military training area.

These arguments do not explain why some bumblebees are much rarer than others. Some bumblebee species such as $B$. subterraneus appear to be relatively rare wherever they occur, and it is interesting that even when transported to the opposite side of the globe in New Zealand, the relative abundance of bumblebee species remains constant. Williams (1988) argued that rare species tended to be those near the edge of their latitudinal range. Such species are presumably poorly adapted to local conditions and thus can only survive in high quality habitats; when these become degraded, they are the first species to disappear. This argument is sensible but does not explain why some species should be rare throughout their range, and it is inconsistent with the abundance of $B$. terrestris and B. lapidarius in the UK when both are near the northern edge of their range. More recently, Williams (2005) found no evidence to support the range edge hypothesis but showed that rare species with low abundance also tended to have small geographic range across Europe. However, this leaves the question as to why these species are rare and have smaller ranges unanswered; Williams suggests that it may be because these species have more specific habitat or climatic requirements. Goulson et al. (2005) present evidence that many of the rarer UK species have more specialized diets, favouring pollen from Fabaceae, while the "mainland ubiquitous" species have broad foraging preferences and readily encompass non-native garden plants in their diets (see 
also Goulson et al. 2002). This could explain differences in abundance between species, for species with narrow diet breadth have access to less resources, and as biotopes are degraded and floral resources decline, these specialists will be the first species to disappear.

At least three UK bumblebee species appear to occupy very different biotopes in different parts of their range. In the Hebrides, B. soroeensis, B. jonellus and B. muscorum are associated to varying degrees with heathland, and all three exploit Calluna and Erica for both nectar and pollen (Goulson et al. 2005). In the south $B$. soroeensis is associated with calcareous grassland, $B$. muscorum with coastal biotopes, and B. jonellus with a range of biotopes including gardens. Clearly even the rarer species can be adaptable with regard to forage and biotope use. For all three of these species the Hebridean and southern UK populations are morphologically distinct and have almost certainly been reproductively isolated for a considerable period of time, but it is unknown whether they exhibit local adaptation to the particular biotopes occupied in each region, or whether populations retain the ability to exploit markedly different biotopes according to availability. That there is at least a degree of local genetic adaptation is evidenced by differences in phenology between geographic regions: $B$. jonellus is an early species in England and nests are usually finished by June or July (Alford 1975), but in the Hebrides it is the last species to emerge from hibernation and worker numbers peak in August and September to coincide with the peak flowering of Calluna (B.D. unpublished data).

In summary, most UK bumblebee species do not have tight biotope associations. Six species are generally widespread and occur in almost all biotopes. The rarer species are not generally found in gardens or intensively farmed land (arable margins, improved pastures), but appear to be restricted to a broad range of rare biotopes that have escaped the ravages of modern agriculture. Perhaps because of the difficulty in bringing them into agricultural production, many of these sites are coastal.

\section{Acknowledgements}


This work was funded by grants from the British Entomology and Natural History Society, English Nature and the Leverhulme Trust to DG. We would like to thank Defence Estates for allowing access to Salisbury Plain Training Area, and Scottish Natural Heritage and RSPB for access to Hebridean sites. Thanks are also due to Kathryn Voce and Vicky Holland for help with fieldwork.

\section{References}

Anon. (1990) Handbook for Phase 1 habitat survey - a technique for environmental audit. Joint Nature Conservation Committee Support Co.

Alford, D.V. (1975) Bumblebees. London: Davis-Poynter.

Alford, D.V. (ed.) (1980) Atlas of the Bumblebees of the British Isles. Institute of Terrestrial Ecology Publications, No. 30 .

Buchmann, S.L. and Nabhan, G.P. (1996) The Forgotten Pollinators. Washington (DC): Island Press.

Corbet, S.A., Williams, I.H. and Osborne, J.L. (1991) Bees and the pollination of crops and wild flowers in the European Community. Bee World 72, 47-59.

Edwards, M. (1998) U.K. Biodiversity Action Plan Bumblebee Working Group Report 1998. Unpublished report for the UK BAP bumblebee working group, Midhurst, UK.

Edwards, M. (1999) U.K. Biodiversity Action Plan Bumblebee Working Group Report 1999. Unpublished report for the UK BAP bumblebee working group, Midhurst, UK.

Edwards, M. (2000) U.K. Biodiversity Action Plan Bumblebee Working Group Report 2000. Unpublished report for the UK BAP bumblebee working group, Midhurst, UK.

Edwards, M. (2001) U.K. Biodiversity Action Plan Bumblebee Working Group Report 2001. Unpublished report for the UK BAP bumblebee working group, Midhurst, UK.

Goulson, D. (2003) Bumblebees; their behaviour and ecology. Oxford: Oxford University Press. Goulson, D. and Darvill, B. (2004). Niche overlap and diet breadth in bumblebees; are rare species more specialized in their choice of flowers? Apidologie 35, 55-64 
Goulson, D. and Hanley, M.E. (2004) Distribution and forage use of exotic bumblebees in South Island, New Zealand. New Zealand J. Ecol. 28, 225-232.

Goulson, D., Hanley, M.E., Darvill, B., Ellis, J.S. and Knight, M.E. (2005) Causes of rarity in bumblebees. Biol. Conserv. 122, 1-8

Goulson, D., Hughes, W.O.H., Derwent, L.C. and Stout, J.C. (2002) Colony growth of the bumblebee, Bombus terrestris, in improved and conventional agricultural and suburban habitats. Oecologia 130, 267-273

Goulson, D. and Williams, P.H. (2001) Bombus hypnorum (Hymenoptera: Apidae), a new British bumblebee? Brit. J. Entomol. Nat. Hist. 14, 129-131.

Grime, J.P., Hodgson, J.G. and Hunt, R. (1988) Comparative Plant Ecology. London: Unwin Hyman. Hopkins, I. (1914) History of the bumblebee in New Zealand: its introduction and results. New Zealand Department of Agriculture, Industry and Commerce 46, 1-29.

Howard, D.C., Watkins, J.W., Clarke, R.T. Barnett, C.L. and Stark, G.J. (2003) Estimating the extent and change in broad habitats in Great Britain. J. Envir. Management 67, 219-227.

Kosior, A. (1995) Changes in the fauna of bumble-bees (Bombus Latr.) and cuckoo-bees (Psithyrus Lep.) of selected regions in southern Poland. In Changes in Fauna of Wild Bees in Europe (J. Banaszak, ed.), pp. 103-111. Bydgoszcz: Pedagogical University.

Osborne, J.L. and Corbet, S.A. (1994) Managing habitats for pollinators in farmland. Asp. Appl. Biol. 40, 207-215.

Osborne, J.L., Williams, I.H. and Corbet, S.A. (1991) Bees, pollination and habitat change in the European community. Bee World 72, 99-116.

Owen, J. (1991) The Ecology of a Garden: the first fifteen years. Cambridge: Cambridge University Press.

Rasmont, P. (1988) Monographie écologique et zoogéographique des bourdons de France et de Belgique (Hymenoptera, Apidae, Bombinae). Ph.D. thesis, Faculté des Sciences Agronomique de l’Etat, Gembloux, Belgium. 
Rasmont, P. (1995) How to restore the Apoid diversity in Belgium and France? Wrong and right ways, or the end of protection paradigm! In Changes in Fauna of Wild Bees in Europe (J. Banaszak, ed.), pp. 53-64. Bydgoszcz: Pedagogical University.

Rich, T.C.G. and Woodruff, E.R. (1996) Changes in the vascular plant floras of England and Scotland between 1930-1960 and 1987-1988: The BSBI monitoring scheme. Biol. Conserv. 75, 217-229.

Westrich, P. (1996) Habitat requirements of central European bees and the problems of partial habitats. In The conservation of bees (A. Matheson, S.L. Buchmann, C. O’Toole, P. Westrich, I.H. Williams, eds.), pp. 2-16. London: Academic Press.

Westrich, P., Schwenninger, H.-R., Dathe, H., Riemann, H., Saure, C., Voith, J. and Weber, K. (1998) Rote Liste der Bienen (Hymenoptera: Apidae). In Rote Liste Gefährdeter Tiere Deutschlands. Ed. by Bundesamt für Naturschutz. Naturschutz 55, Bonn, Schriftenr. Landschaftspf, pp. 119-129.

Williams, P.H. (1982) The distribution and decline of British bumble bees (Bombus Latr). J. Apic. Res. 21, 236-245.

Williams, P.H. (1986) Environmental change and the distribution of British bumble bees (Bombus Latr.). Bee World 67, 50-61.

Williams, P.H. (1988) Habitat use by bumble bees (Bombus spp.). Ecol. Entomol. 13, 223-237.

Williams, P.H. (1989) Bumble bees - and their decline in Britain. Ilford: Central Association of BeeKeepers.

Williams, P.H. (2005) Does specialization explain rarity and decline among British bumblebees? A response to Goulson et al.. Biol. Conserv. 122, 33-43. 
Table 1. Numbers of populations of different bumblebee species identified in a range of biotopes in southern UK. The total numbers of each biotope type surveyed are given in the final column. a)

Southern UK; b) Hebrides; c) New Zealand. Abbreviations: pasc $=$ B. pascuorum, terr $=$ B. terrestris, lapi $=$ B. lapidarius, luco = B. lucorum, magn $=$ B. magnus, prat $=B$. pratorum, hort $=B$. hortorum, sylv $=B$. sylvarum, jone $=B$. jonellus, musc slad $=B$. muscorum sladeni, musc smith $=B$. muscorum smithianus, musc pall $=$ B. muscorum pallidus, ruderar $=B$. ruderarius, soro $=B$. soroeensis, ruderat $=B$. ruderatus, subt $=B$. subterraneus, dist $=B$. distinguendus, hypn $=B$. hypnorum .

\section{musc musc musc}

a) Southern UK $\quad$ pasc terr lapi luco magn prat hort hum sylv jone hypn slad smith pall ruderar soro ruderat subt $\mathrm{N}$

\begin{tabular}{|c|c|c|c|c|c|c|c|c|c|c|c|c|c|c|c|c|c|c|}
\hline Coastal sand dunes & 2 & 2 & 3 & 0 & - & 0 & 0 & 1 & 1 & 0 & 0 & 0 & - & - & 0 & 0 & 0 & -3 \\
\hline Coastal salt Marsh & 0 & 1 & 1 & 1 & - & 0 & 0 & 1 & 1 & 0 & 0 & 0 & - & - & 0 & 0 & 0 & -1 \\
\hline Vegetated shingle & 1 & 1 & 1 & 1 & - & 1 & 1 & 1 & 1 & 0 & 0 & 1 & - & - & 0 & 0 & 0 & -1 \\
\hline Grazing marsh & 1 & 1 & 1 & 1 & - & 0 & 1 & 1 & 2 & 0 & 0 & 1 & - & - & 0 & 0 & 1 & -2 \\
\hline Fen & 1 & 1 & 1 & 1 & - & 0 & 1 & 0 & 1 & 0 & 0 & 1 & - & - & 0 & 0 & 0 & -1 \\
\hline Lowland dry acid grassl. & 1 & 1 & 1 & 2 & - & 0 & 0 & 0 & 0 & 0 & 0 & 0 & - & - & 0 & 0 & 0 & -2 \\
\hline Lowland unimp. mead. & 5 & 5 & 5 & 4 & - & 4 & 4 & 0 & 0 & 0 & 0 & 0 & - & - & 0 & 0 & 0 & \\
\hline Lowland calc. grassl. & 11 & 9 & 12 & 8 & - & 5 & 7 & 5 & 2 & 1 & 0 & 2 & - & - & 2 & 3 & 1 & -12 \\
\hline Semi-improved grassl. & 7 & 5 & 7 & 4 & - & 5 & 3 & 0 & 0 & 0 & 0 & 0 & - & - & 1 & 0 & 0 & -7 \\
\hline Improved grassland & 0 & 2 & 1 & 0 & - & 1 & 0 & 0 & 0 & 0 & 0 & 0 & - & - & 0 & 0 & 0 & \\
\hline Arable margin & 7 & 5 & 6 & 0 & - & 6 & 5 & 0 & 0 & 0 & 1 & 0 & - & - & 0 & & 0 & \\
\hline Gardens & 10 & 10 & 7 & 8 & - & 9 & 7 & 0 & 0 & 2 & 4 & 0 & - & - & 0 & & 0 & -10 \\
\hline Brownfield & 2 & 2 & 2 & 2 & - & 1 & 1 & 1 & 1 & 0 & 0 & 0 & - & - & 0 & & 0 & -2 \\
\hline Woodland & 4 & 4 & 1 & 3 & - & 3 & 4 & 0 & 0 & 0 & 1 & 0 & - & - & 0 & & 0 & -5 \\
\hline Lowland heath & 4 & 5 & 2 & 5 & - & 1 & 0 & 0 & 0 & 2 & 0 & 0 & - & - & 0 & & 0 & -6 \\
\hline Total & 56 & 54 & 51 & 40 & & 36 & 34 & 10 & 9 & 5 & 6 & 5 & & & 3 & 3 & 2 & \\
\hline \multicolumn{19}{|l|}{ b) Hebrides } \\
\hline Coastal sand dunes & 0 & 0 & 2 & 2 & 3 & - & 3 & - & - & 0 & & - & 3 & 1 & 2 & 0 & - & -5 \\
\hline Upland heath & 0 & 0 & 2 & 3 & 8 & - & 2 & - & - & 14 & & - & 11 & 3 & 0 & 2 & - & -14 \\
\hline Fen & 0 & 0 & 0 & 1 & 3 & - & 0 & - & - & 2 & & - & 2 & 0 & 0 & 0 & - & -3 \\
\hline Lowland dry acid grassl. & 2 & 0 & 1 & 1 & 0 & - & 2 & - & - & 0 & & - & 0 & 3 & 2 & 0 & - & -3 \\
\hline Lowland unimp. mead. & 0 & 0 & 1 & 1 & 1 & - & 1 & - & - & 1 & & - & 1 & 0 & 0 & 0 & - & 1 \\
\hline Machair & 0 & 0 & 2 & 0 & 1 & - & 2 & - & - & 1 & & - & 3 & 1 & 2 & 0 & - & 4 \\
\hline Semi-improved grassl. & 4 & 0 & 1 & 4 & 4 & - & 6 & - & - & 1 & & - & 5 & 1 & 2 & 0 & - & -6 \\
\hline Gardens & 7 & 0 & 1 & 6 & 6 & - & 8 & - & - & 2 & & - & 2 & 0 & 1 & 0 & - & -8 \\
\hline Road verges & 6 & 0 & 1 & 4 & 3 & - & 5 & - & - & 0 & & - & 4 & 0 & 1 & 0 & - & -14 \\
\hline Total & 19 & 0 & 11 & 22 & 29 & & 29 & & & 21 & & & 31 & 9 & 10 & 2 & & \\
\hline
\end{tabular}

c) New Zealand

\begin{tabular}{|c|c|c|c|c|c|c|c|c|c|c|c|c|c|c|c|}
\hline Rough pasture & -20 & - & - & - & - 18 & - & - & - & - & - & - & - & - & 13 & 321 \\
\hline Road verges & - 19 & - & - & - & 16 & - & - & - & - & - & - & - & - & 12 & 013 \\
\hline Lake margin & -10 & - & - & - & 9 & - & - & - & - & - & - & - & - & 9 & 710 \\
\hline Shingle river margins & -12 & - & - & - & -11 & - & - & - & - & - & - & - & - & 5 & 012 \\
\hline Non-native scrub & -12 & - & - & - & 9 & - & - & - & - & - & - & - & - & 6 & 012 \\
\hline Improved pasture & 9 & - & - & - & -10 & - & - & - & - & - & - & - & - & 6 & 011 \\
\hline Semi-improved pasture & 6 & - & - & - & 5 & - & - & - & - & - & - & - & - & 4 & 06 \\
\hline Gardens & 3 & - & - & - & 1 & - & - & - & - & - & - & - & - & 1 & 03 \\
\hline Native forest & 4 & - & - & - & 0 & - & - & - & - & - & - & - & - & 0 & 05 \\
\hline Total & 95 & & & & 79 & & & & & & & & & 56 & 10 \\
\hline
\end{tabular}


Table 2. Loadings for principal component one and two extracted from principal components analyses of the proportion of populations of different bumblebee species recorded in different biotope types.

\begin{tabular}{|c|c|c|c|c|c|c|}
\hline & \multicolumn{2}{|c|}{ Southern UK } & \multicolumn{2}{|c|}{ Hebrides } & \multicolumn{2}{|c|}{ New Zealand } \\
\hline & PC1 & $\mathrm{PC} 2$ & PC1 & $\mathrm{PC} 2$ & PC1 & $\mathrm{PC} 2$ \\
\hline Coastal sand dunes & -0.544 & 0.723 & -0.549 & 0.710 & & \\
\hline Coastal salt Marsh & -0.651 & 0.655 & & & & \\
\hline Vegetated shingle & -0.666 & 0.300 & & & & \\
\hline Grazing marsh & -0.596 & -0.152 & & & & \\
\hline Fen & -0.522 & 0.150 & 0.051 & 0.483 & & \\
\hline Lowland dry acid grassland & 0.302 & 0.347 & 0.361 & 0.683 & & \\
\hline Lowland unimproved meadows & 0.635 & 0.488 & 0.181 & -0.307 & & \\
\hline Lowland calcareous grassland & -0.507 & -0.604 & & & & \\
\hline Semi-improved grassland & 0.365 & -0.048 & 0.872 & 0.337 & 0.967 & -0.197 \\
\hline Improved grassland & 0.414 & 0.391 & & & 0.937 & -0.343 \\
\hline Arable margin & 0.767 & 0.353 & & & & \\
\hline Gardens & 0.745 & 0.062 & 0.923 & 0.103 & 0.866 & 0.477 \\
\hline Brownfield & -0.433 & 0.840 & & & & \\
\hline Woodland & 0.776 & 0.289 & & & & \\
\hline Lowland heath & 0.260 & -0.137 & & & & \\
\hline Upland heathland/ moorland & & & -0.359 & -0.860 & & \\
\hline Machair & & & -0.683 & 0.618 & & \\
\hline Road verges, waste ground & & & 0.909 & 0.262 & 0.977 & -0.183 \\
\hline Rough pasture & & & & & -0.997 & -0.078 \\
\hline Lake margin & & & & & -0.994 & 0.105 \\
\hline Shingle river margins & & & & & 0.957 & -0.088 \\
\hline Non-native scrub & & & & & 1.000 & -0.029 \\
\hline Native New Zealand forest & & & & & 0.476 & 0.876 \\
\hline$\%$ of variation explained & 32.3 & 19.3 & 37.7 & 28.5 & 84.9 & 13.5 \\
\hline
\end{tabular}




\section{Figure Legends}

Fig. 1. The proportion of populations of different bumblebee species recorded in different biotope types was subjected to principal components analysis, and the first two components are plotted here. Separate analyses were conducted for data from: a) southern UK; b) Hebrides; c) New Zealand. It must be noted that the biotopes present and the principal components extracted in each analysis are different, so the relative positions in the three parts of the figure are not directly comparable. Circles indicate the biotopes associated with particular areas of each plot. 
a) Southern UK

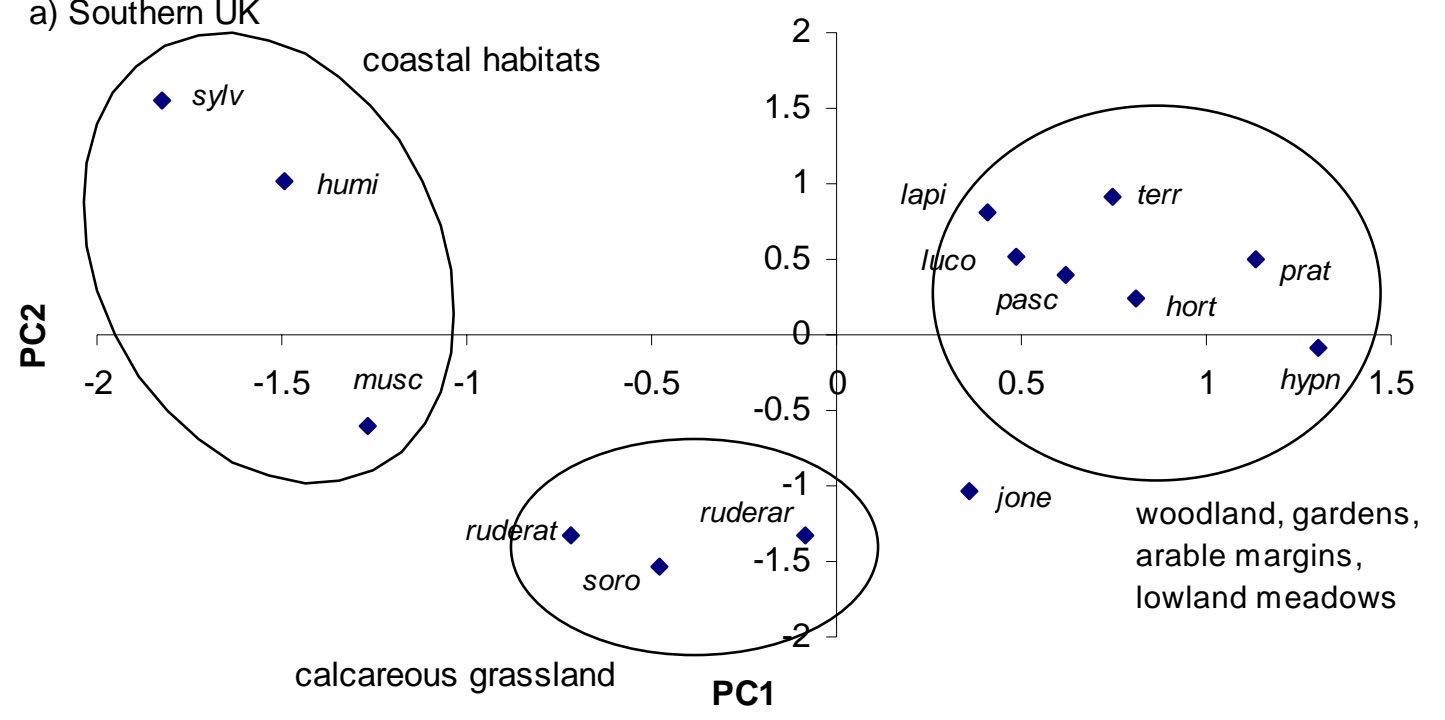

b) Hebrides machair, dunes

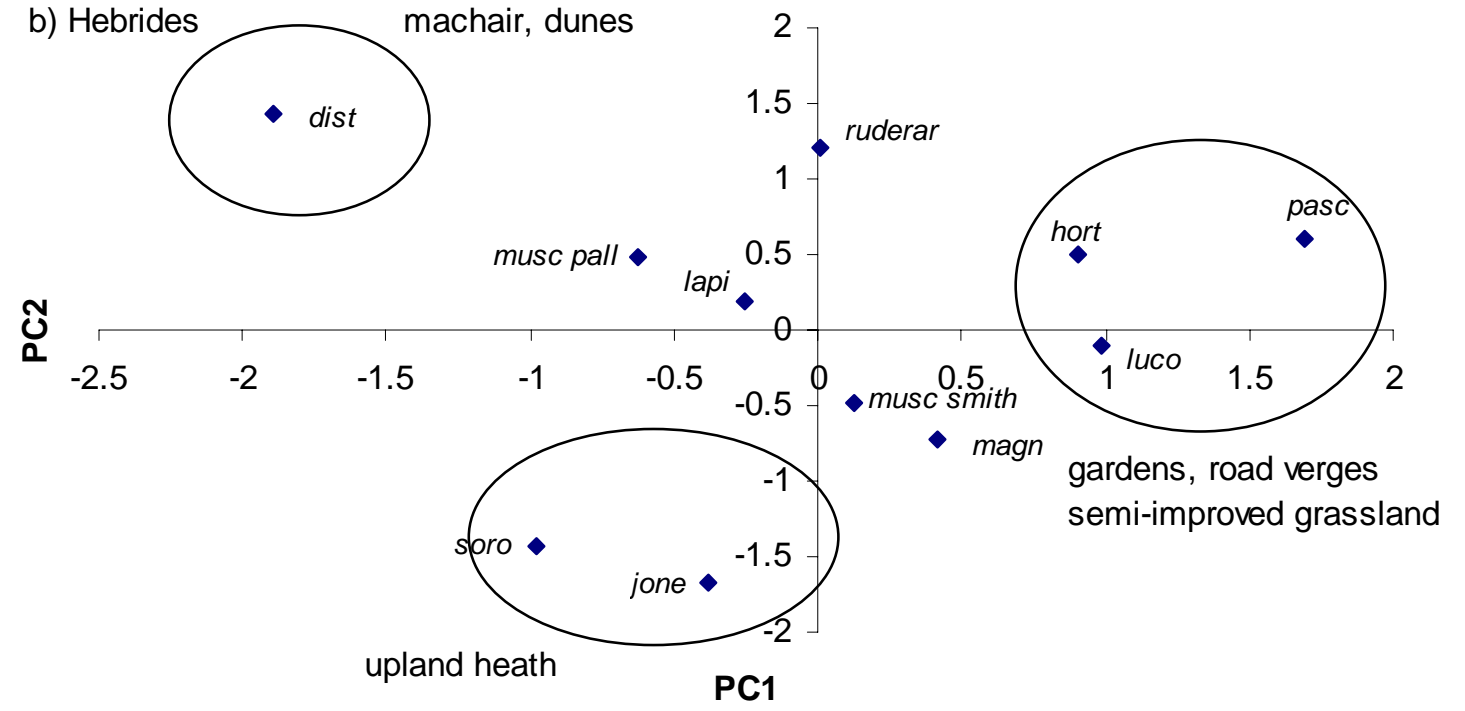

c) New Zealand

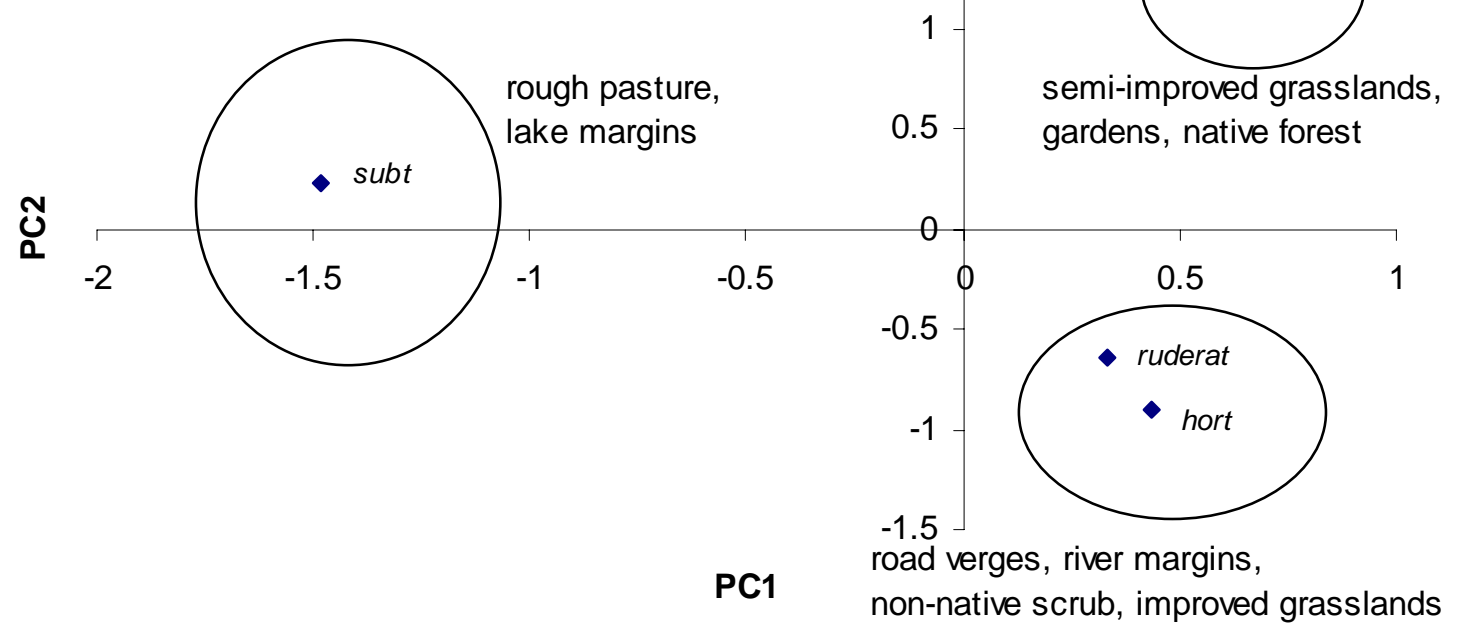

